\title{
ANALISIS USAHA BUDIDAYA RUMPUT LAUT (Eucheuma cottonii) DI PULAU PARI, KEPULAUAN SERIBU
}

\author{
Husnul Syarifah Achsya Dinda ${ }^{1}$, Edward Danakusumah ${ }^{2}$, dan Urip Rahmani ${ }^{3}$ \\ ${ }^{1,2,3)}$ Fakultas Perikanan dan Ilmu Kelautan Universitas Satya Negara Indonesia, Jakarta
}

\begin{abstract}
Seaweed is one of the potential fishery resources that have been developed in Indonesia with good prospects. Because the demand of the seaweed increase it have a appect of the production of seaweed. This is reseach use primary data, secondary data followed with the related literature, using data analysis feasibility revenues $(R C$ Ratio, BEP,PP,ROI) and analysis investment criteria (NPV, Net B/C, IRR). The teknik that use by the fisherman of a seaweed in Pari Island, is a fandemental general realeas teknik the proses star from sead, maintanence of the growing seaweed and cultivation. The result of the analysis showing the the value $R / C: 3,02, B E P: R p$. 4.385.799,-, ROI: 1,2\% and PP: 4,08 and the result of investement of criteria showing the value NPV: Rp. 30.619.928, Net B/C: 2,529 and IRR: 89,23\%. the result of the cultivation is $600 \mathrm{~kg}$ of seaweed.
\end{abstract}

Keyword :Growing seaweed, Eucheuma cottonii, Pari Island

\begin{abstract}
ABSTRAK
Rumput laut merupakan salah satu potensi sumberdaya yang telah dikembangkan di Indonesia dengan memiliki prospek yang baik.Karena tingginya jumlah permintaan rumput laut maka menyebabkan produksi budidaya rumput laut makin meningkat. Metode dalam penelitian ini menggunakan data primer, sekunder serta studi literatur yang terkait, dengan menggunakan analisis data kelayakan pendapatan usaha (R-C Ratio, BEP, PP, ROI) dan analisis kriteria investasi (NPV, Net B/C, IRR). Teknik budidaya yang digunakan oleh nelayan rumput laut adalah teknik lepas dasar yang umum dilakukan oleh para nelayan di Pulau Pari, serta proses budidaya mulai dari pembibitan, pemeliharaan masa tanam dan pemanenan. Hasil dari analisis kelayakan pendapatan usaha menjukan nilai R/C: 3,02. BEP: Rp.4385.799,-. ROI: 1,2\%, dan PP: 4,08. Hasil dari analisis lriteria investasi dengan nilai NPV: Rp. 30.619.928. Net B/C: 2,529 dan IRR 89,23\%. Dengan hasil panen yang dicapai mendapatkan hasil $600 \mathrm{Kg}$ rumput laut.
\end{abstract}

Kata Kunci :Budidaya rumput laut, Eucheuma cottonii, Pulau Pari. 


\section{PENDAHULUAN}

Rumput laut di Indonesia merupakan salah satu potensi sumberdaya perairan yang sejak lama dimanfaatkan sebagai bahan pangan dan obat-obatan.Saat ini pemanfatan rumput laut telah mengalami peningkatan (Khordi dan Ghufran, 2010).Seiring peningkatan pemanfaatan rumput laut yang tinggi maka permintaan pasar pun semakin tinggi juga.Salah satu dari keberhasilan budidaya rumput laut adalah dengan cara memilih lokasi yang tepat untuk penanaman rumput laut. Budidaya rumput laut dilihat dari aspek teknis usaha ini sangat mudah dilakukan, selain itu dilihat dari prospek usaha budidaya rumput laut sangat menjanjikan karena dimulai dengan modal yang tidak terlalu banyak maka bisa mengasilkan keuntungan yang cukup tinggi dari usaha budidaya rumput laut (Anggadiredja, et al, 2011).

Propinsi DKI Jakarta mengembangkan budidaya rumput laut yang dilakukan di Pulau Pari Kepulauan Seribu. Karena itu untuk melihat pertumbuhan budidaya rumput laut dengan teknik lepas dasar perlu diamati. Tujuan dari penelitian ini untuk mengetahui aspek teknis dan menghitung analisis kelayakan usaha budidaya rumput laut di PulauPari sehingga nantinya dapat dikembangkan kembali usaha budidaya rumput laut yang sempat terhenti.

\section{METODOLOGI}

Penelitian ini dilaksanakan pada bulan Nobember sampai Desember 2013 yang bertempat di Pulau Pari, Kepulaun Seribu.Adapun alat yang digunakan adalah; gerobak panen, pisau, perahu, alat tulis, kamera, thermometer, sechi disk, refratometer dan kertas lakmus. Alat yang digunakan adalah bibit rumput laut Eucheuma cottonii, tali tambang besar ukuran $6 \mathrm{~mm}$, tali tambang kecil ukuran $3 \mathrm{~mm}$, pelampung dan bambu. Metode penelitian yang digunakan adalah metode pengumpulan data primer, sekunder serta studi literatur yang berhubungan dengan kegiatan analisis usaha budidaya rumput laut.Budidaya rumput laut dilakukan langsung kegiatan operasional budidaya dengan menggunakan teknik lepas dasar, bibit rumput laut dapat diperoleh di Pulau Pari kemudian proses pemeliharaan dan pemanenan. Pemeriksaan kontruksi teknik lepas dasar dilakukan setiap seminggu sekali saat air surut atau pada sore hari.Rumput laut Eucheuma cottonii dapat dipanen setelah 40 hari masa pemeliharaannya selanjutnya hasil dari panen budidaya rumput laut dapat dibawa ketengkulak atau dapat dijual secara langsung pada konsumen.

\section{Analisis Data}

Analisis data yang dilakukan dengan menghitung analisis kelayakan usaha budidaya rumput laut yang dapat dijelaskan pada rumus-rumus berikut ini:

\section{1) Analisis R/C Ratio}

Analisis imbangan penerimaan dan biaya ini bertujuan untuk mengetahui hasil yang diperoleh dari suatu kegiatan usaha dengan rumus (Hernanto, 1989): 
Dengan kriteria:

$\mathrm{R} / \mathrm{C}>1$ : usaha menguntungkan

$\mathrm{R} / \mathrm{C}=1:$ usaha tidak menguntungkan dan tidak rugi

$\mathrm{R} / \mathrm{C}<1$ : usaha rugi

\section{2) Analisis Break Event Point (BEP)}

Analisis ini untuk melihat titik impas yang bertujuan mengetahui sampai batas mana usaha yang dilakukan bisa memberikan keuntungan.Analisis ini menyatakan sebagai contoh jumlah tangkapan minimal yang harus diperoleh setiap tahun pada tingkat untung atau tidak rugi. Rumus yang digunakan adalah (Rahardi et al , 1993):

\section{3) Analisis Payback Period}

Payback Period adalah analisis pengembalian modal yangbertujuan untuk mengetahui berapa lama waktu yang diperlukan (dalam tahun atau bulan) untuk menutupi investasi dengan rumus (Hernanto, 1989):

\section{4) Analisis Return On Investment}

Return On Investement (ROI) adalah analisis tingkat pengembalian investasi yang merupakan analisis usaha yang digunakan untuk mengetahui berapa prosentase kemungkinan pengembalian keuntungan dari investasi yang ditanamkan dengan asumsi pendapatan setiap bulan atau tetap (Hernanto, 1989).

Rumus ROI adalah:

\section{Analisis Kriteria Investasi}

Analisis ini bertujuan untuk mengetahui apakah suatu usaha layak untuk dikembangkan atau tidak.Menurut Djamin (1993) dalam menghitung analisis ini dapat digunakan analisis sebagai berikut:

\section{1) Net Present Value (NPV)}

NPV adalah selisih antara Present Value (PV) arus benefit dengan PV arus biaya. Nilai NPV dapat dihitung dengan menggunakan rumus:

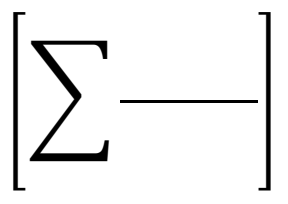


Dimana:

bt = annual gross benefit

ct $=$ annual costs

$(1+\mathrm{i})^{\mathrm{t}}=$ discounting factor $\left(\mathrm{D}_{\mathrm{F}}\right)$

Ko = initial investement

$\mathrm{t} \quad=\mathrm{n}$. menunjukkan umur ekonomis proyek

$\mathrm{t} \quad=1$, artinya tahun pertama proyek

Dengan kriteria:

NVP $>0 \quad$ : usaha layak untuk dijalankan

$\mathrm{NVP}=0 \quad$ : usaha layak/tidak layak dijalankan

NVP $<0 \quad$ : usaha tidak layak untuk dijalankan

\section{2) Benefit Cost Ratio (B/C)}

Benefit Cost Ratio adalah perbandingan antara total nilai sekarang dari penerimaan bersih yang bersifat positif dan total nilai sekarang penerimaan bersih bersifat negatif. Rumus yang digunakan adalah:

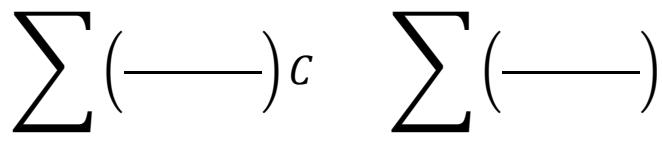

$($ Project Total Cost $=\mathrm{Ko}+\mathrm{C})$

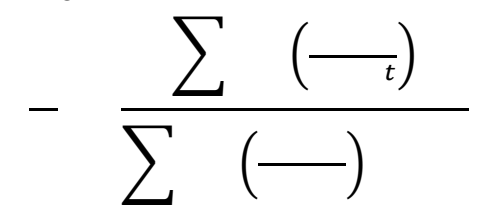

Dengan kriteria:

Net $\mathrm{B} / \mathrm{C} \geq 1 \quad$ : usaha layak dijalankan

Net $\mathrm{B} / \mathrm{C}<1$ : usaha tidak layak dijalankan

\section{3) Internal Rate of Return (IRR)}

Untuk menentukan berapa tepatnya tingkat bunga yang ideal, caranya adalah dengan melakukan percobaan-percobaan terus atau dengan menggunakan metode interpolasi/penyisipan diantara bunga yang lebih rendah (yang menghasilkan NPV positif) dengan tingkat bunga yang lebih tinggi (yang menghasilkan NPV negative) yang dapat dituangkan dalam rumus:

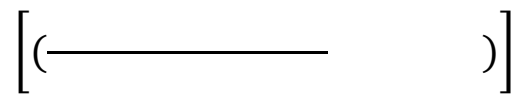

Dimana:

i' = tingkat suku bunga yang digunakan untuk menghasilkan present value positif 
ii” = tingkat suku bunga yang digunakan untuk menghasilkan present

value negatif

$\mathrm{PVP}=$ present value positif

$\mathrm{PVN}=$ present value negatif

Dengan kriteria:

IRR $>\mathrm{i} \quad$ : usaha layak dijalankan

IRR $<\mathrm{i} \quad$ : usaha tidak layak dijalankan

\section{HASIL DAN PEMBAHASAN}

\section{Gambaran Umum Budidaya Rumput Laut}

Beberapa gambaran umum tentang budidaya rumput laut di Pulau Pari, Kepulauan Seribu sebagai berikut:

1. Salah satu keberhasilan budidaya rumput laut adalah pemilihan lokasi yang tepat. Letak lokasi penanaman berjarak 5-10 m dari garis pantai. Lokasi penanaman harus mempunyai pergerakan air yang cukup bagus dan ditumbuhi oleh komunitas yang terdiri dari beberapa jenis makro alga.

2. Pemilihan benih berasal dari Pulau Pari karena benih yang berasal dari satu jenis rumput laut lebih murni. Cirir-ciri benih yang baik adalah benih halus muda, bersih dan segara agar memberikan pertumbuhan yang optimal.

3. Penanaman rmput laut menggunakan teknik lepas dasar dengan cara pemasangan bibit rumput laut pada tali ris kecil, kemudian dapat diikat pada tali ris utama dengan jarak $25-30 \mathrm{~cm}$. Cara penanamannya dengan mengikat bibit rumput laut pada ujung tali ris utama kepatok yang terbuat dari kayu, lalu kayu ditancapkan ke dasar perairan dengan bantuan besi panjang atau batu. Kemudian tali ris utama beserta bibit rumput laut yang telah diikatkan dibentangkan dengan alur mundur atau jalan ke belakang. Biasanya pada satu baris terdapat 3 tali yang disambung panjangnya 10 meter, jadi dalam satu baris terdapat 30 meter tali yang telah diikatkan bibit rumput laut. Setelah ujung tali yang terakhir diikatkan lagi dengan kayu dan kayu tersebut ditancapkan lagi ke dasar parairan. Setelah selesai, dipasangkan pelampung yang terbuat dari sterofom dengan jarak antar pelampung 1-2 $\mathrm{m}$ yang diikat pada tali ris utama.

4. Pemeliharaan yang dilakukan biasanya memeriksa tanaman, membersihkan sampah-sampah yang menempel, baik pada tali maupun pada rumput laut yang ditanam, memeriksa rumput laut yang terkena penyakit.

5. Rumput laut dipanen setelah mencapai umur lebih dari 40 hari setalah tanam. Cara pemanenan rumput laut dengan cara melepas patok yang ditancapkan di 
dasar perairan kemudian tali yang diikat pada patok dilepaskan setelah itu rumput laut yang terikat dengan tali dapat panen dan ditaruh diperahu sampan dan hasil panen tersebut diangkat ke darat

6. Pemasaran yang dilakukan oleh petani rumput laut dengan menjual ke pengepul atau dijual langsung pada konsumen akhir. Para petani menjual harga rumput laut basah dengan harga Rp. 6000/kg.

\section{Parameter Kulaitas Air}

Parameter kualitas perairan yang diukur dalam penelitian budidaya rmput laut seperti suhu, salinitas, $\mathrm{pH}$ dan kecerahan pada tiap minggunya dapat dijelaskan pada Tabel 1. Tabel 1. Parameter Kualitas Air

\begin{tabular}{|r|l|c|r|r|r|r|r|r|r|}
\hline \multirow{2}{*}{ No } & \multirow{2}{*}{ Parameter } & \multirow{2}{*}{ Satuan } & \multicolumn{9}{|c|}{ Minggu } \\
\cline { 4 - 10 } & & & \multicolumn{1}{c|}{0} & 1 & \multicolumn{1}{c|}{2} & \multicolumn{1}{c|}{3} & \multicolumn{1}{c|}{5} & \multicolumn{1}{c|}{6} \\
\hline 1 & Suhu & ${ }^{\circ} \mathrm{C}$ & 29 & 27 & 31 & 31 & 30 & 28 & 30 \\
\hline 2 & Salintas & \% & 31 & 31 & 31 & 32 & 31 & 31 & 31 \\
\hline 3 & $\mathrm{pH}$ & - & 8,1 & 8,0 & 8,1 & 8,4 & 8,3 & 8,0 & 8,3 \\
\hline 4 & Kecerahan & $\mathrm{M}$ & 1 & 1 & 1 & 1 & 1 & 1 & 1 \\
\hline
\end{tabular}

\section{Analisis Kelayakan Usaha Penerimaan Usaha}

Berdasarkan perhitungan penerimaan usaha budidaya rumput laut dalam waktu satu tahun mendapatkan hasil sebesar Rp. 14.400.000,- dari jumlah panen yang dikalikan dengan harga jual dan dikalikan lagi dengan produksi pertahun. Petani mendapatkan keuntungan pertahun sebesar Rp. 9.638.668,- dari total penerimaan dikurangi dengan total biaya. Dengan demikian para petani budidaya rumput laut banyak mengembangkan usaha sampingan ini yang menambah pendapatan para petani di Pulau Pari.Biasanya harga jual rumput laut di Pulau Pari adalah Rp. $6.000 / \mathrm{kg}$ untuk rumput laut basah.Produksi rumput mendapatkan hasil sebanyak 600 $\mathrm{Kg}$ dalam satu kali panen. Petani rumput laut dalam satu tahun biasanya bisa 4 (empat) kali panen rumput laut..

\section{Biaya Investasi}

Biaya investasi untuk usaha budidaya rumput laut sebesar Rp. 3.281.500 yang terdiri dari kebutuhan biaya penanaman seeperti tali ris besar, tali ris kecil, pelampung, kayu, pisau, sampan, gerobak yang dapat dilihat pada Tabel 2. 
Tabel 2. Rincian Biaya Investasi

\begin{tabular}{|l|c|r|r|r|r|}
\hline \multicolumn{1}{|c|}{ Uraian } & Satuan & Jumlah & \multicolumn{1}{c|}{$\begin{array}{c}\text { Harga } \\
\text { Satuan } \\
\text { (Rp) }\end{array}$} & \multicolumn{1}{c|}{$\begin{array}{c}\text { Jumlah/ } \\
\text { Produksi } \\
(\mathrm{Rp})\end{array}$} & $\begin{array}{c}\text { Jumlah/ } \\
\text { Tahun } \\
\text { (Rp) }\end{array}$ \\
\hline $\begin{array}{l}\text { Tali Tambang besar } \\
\text { berdiameter 6mm }\end{array}$ & $\mathrm{Kg}$ & 2 & 30.000 & 60.000 & 60.000 \\
\hline $\begin{array}{l}\text { TaliTambang kecil } \\
\text { beridameter 3 mm }\end{array}$ & $\mathrm{Kg}$ & 1 & 15.000 & 15.000 & 15.000 \\
\hline Perahu Sampan & Unit & 1 & 2.000 .000 & 2.000 .000 & 2.000 .000 \\
\hline Gerobak & Unit & 1 & 800.000 & 800.000 & 800.000 \\
\hline Pisau & Buah & 1 & 20.000 & 20.000 & 20.000 \\
\hline Kayu & Buah & 16 & 5.000 & 80.000 & 320.000 \\
\hline Pelampung & Buah & 190 & 350 & 66.500 & 66.500 \\
\hline Total & & & & & 3.251 .500 \\
\hline
\end{tabular}

\section{Biaya Produksi}

Biaya produksi adalah biaya selama usaha budidaya rumput laut dilakukan, biaya produksi terdiri atas biaya tetap dan biaya variabel. Biaya tetap per tahun untuk usaha budidaya rumput laut sebesar Rp. 4.221.332,- komponennya terdiri dari upah panen, biaya penyusutan dan biaya perawan. Sedangkan untuk biaya variabel yang dikeluarkan per tahun sebesar Rp. 540.000.- untuk pembelian bibit rumput laut.

\section{Analisis Imbangan Penerimaan dan Biaya ( $R$ - $C$ Ratio)}

Analisis imbangan penerimaan dan biaya menunjukkan sejauh mana pengaruh perubahan biaya oprasional terhadap penerimaan usaha budidaya rumput laut. Nilai $R-C$ Ratio pada usaha budidaya rumput laut adalah sebesar 3,02 angka ini menunjukan usaha budidaya rumput laut dapat dikembangkan karena nilai $\mathrm{R} / \mathrm{C}>1$ yang artinya dalam 1 rupiah yang dikeluarkan bisa memberikan penerimaan sebesar 3,02 rupiah

\section{Analisis Break Event Point (BEP)}

Analisis ini digunakan untuk menentukan nilai titik impas dari suatu penjualan agar suatu perusahaan tidak untung dan tidak rugi. Analisis ini dapat dihitung berdasarkan perbandingan antara biaya variabel, biaya tetap dan penerimaan total selama 1 tahun produksi budidaya rumput laut. Hasil perhitungan BEP pada usaha budidaya rumput laut menunjukkan hasil Rp. 4.385.799,-- yang berarti usaha budidaya rumput laut akan mencapai titik impas jika dapat penerimaan sebesar Rp. 4.385.799,-- 


\section{Analisis Payback Period (PP)}

Perhitungan PP pada usaha budidaya rumput laut di Pulau Pari menunjukkan hasil 4,08 bulan atau sekitar 4 bulan, 8 hari yang berarti investasi yang ditanam pada usaha budidaya rumput laut akan kembali setelah jangka waktu 4 bulan 8 hari.

\section{Analisis Return of Investement (ROI)}

Analisis ini untuk mengetahui beberapa prosentase kemungkinan pengembalian keuntungan dari investasi yang ditanamkan dengan asumsi pendapatan setiap bulan atau tahun tetap. Nilai ROI untuk usaha budidaya rumput laut yaitu sebesar $1,2 \%$ dari investasi yang ditanamkan pada usaha budidaya rumput laut di Pulau Pari.

\section{Analisis Kriteria Investasi Net Present Value (NPV)}

Perhitungan nilai NPV pada perhitungan analisis kriteria investasi memperoleh nilai NPV sebesar Rp. 30.619.928,-artinya investasi awal tahun ke 0 usaha mendapatkan hasil Rp. 3.281 .500 pada tahun ke 5 akan memperoleh hasil sebesar Rp. 30.619.928,- hal ini menunjukkan usaha budidaya rumput laut layak untuk dijalankan.

\section{Net Benefit Cost Ratio (Net B/C)}

Nilai Net B/C pada usaha budidaya rumput laut merupakan analisis yang masih dalam keadaan kotor, dengan analisis ini dapat melihat kelayakan usaha. Nilai benefit kotor sebesar Rp. 50.648.130 dibagi dengan cost kotor sebesar Rp. 20.028.202 yang dapat diperoleh nilai $\mathrm{Net} B / \mathrm{C}$ yaitu sebesar 2,529. Hal ini menunjukkan kontribusi manfaat bersih selama terhadap biaya selama umur proyek 5 tahun dengan suku bunga $13 \%$.

\section{Internal Rate of Return (IRR)}

Perhitungan IRR dilakukan untuk mengetahui besarnya tingkat suku bunga yang dapat menyebabkan nilai NPV bernilai nol. Berdasarkan perhitungan nilai IRR dengan tingkat suku bunga 13\% mendapatkan hasil sebesar 89,23\%yang artinya usaha budidaya rumput laut dapat menyebabkan nilai NPV bernilai nol pada tingkat suku bunga $89,23 \%$. Hal ini menunjukkan usaha budidaya rumput laut layak untuk dijalankan 


\section{Kesimpulan}

Hasil dari pengamatan dan analisis usaha budidaya rumput laut Eucheuma cottonii dapat disimpulkan sebagai berikut:

1) Budidaya rumput laut di Pulau Pari Kepulauan Seribu perlu dikembangkan kembali, sebab dilihat dari penelitian ini perkembangan rumput laut terlihat baik sampai dengan hasil panen yang mencapai $600 \mathrm{Kg}$ dari bibit 67,5 kg.

2) Hasil dari analisis usaha yang dilakukan penulis menujukan hasil yang baik dan bisa dikembangkan lagi usaha rumput laut ini. Terdapat penerimaan pertahun yang diperoleh sebesar Rp. 14.400.000,- dengan keuntungan yang diterima nelayan pertahun sebesar Rp. 9.638.668,-- Nilai R/C yang diperoleh adalah 3,02, dengan angka ini menujukkan usaha dapat dikembangkan karena ini $\mathrm{R} / \mathrm{C}>1$. Nilai BEP adalah Rp. 4.385.799,-. Nilai ROI sebesar 1,2\% yang berarti presentase nilai keuntungan yang diperoleh dari jumlah yang diinvestasikan dalam jangka satu tahun. Nilai PP yang diperoleh sebesar 4,08 bulan angka ini menunjukkan bahwa dana investasi yang dikeluarkan akan kembali dalam jangka waktu 4 bulan 8 hari.

3) Hasil analisis usaha kriteria investasi dengan cara menghitung nilai NPV, Net B/C dan IRR yang akan menunjukkan suatu usaha budidaya rumput laut layak atau tidak untuk dijalankan. Dari nilai NPV pada tahun ke 5 mendapatkan hasil Rp. 30.619.928. Nilai Net B/C bernilai 2,529 hal ini menunjukkan kontribusi manfaat bersih terhadap biaya selama umur proyek 5 tahun dengan tingkat suku bunga 13\%. Berdasarkan perhitungan nilai IRR pada tingkat suku bunga $13 \%$ yang menyebabkan nilai NPV bernilai nol pada tingkat suku bunga sebesar 89,23\%. .

\section{Saran}

Saran pada penelitian ini pada usaha budidaya rumput laut Eucheuma cottonii di Pulau Pari Kepulauan Seribu perlu dikembangkan kembali, serta peran dari intasi pemerintahan mengenai perkembangan budidaya rumput laut perlu diperhatikan lagi, karena dilihat dari segi analisis usaha budiaya rumput laut sangat membantu juga untuk perekonomian para nelayan di Pulau Pari

\section{Ucapan Terimakasih}

Ucapan terimakasih kepada Bapak Dr. Ir. Edward Danakusumah.M.Sc dan Ibu Dr. Ir. Urip Rahmani.M.Si selaku dosen pembimbing. Ibu Dr. Ir. Dwi Ernaningsih. M.Si selaku Dekan FPIK yang memberikan petunjuk, arahan dan bimbingan demi kesuksesan penulis.Serta kedua orang tua, keluarga besar dan kawan-kawan yang selalu memberikan doa dan motivasi dalam penulisan ini. 


\section{DAFTAR PUSTAKA}

Anggadiredja Jana, T.A. Zatnika, H, Purwoto dan Sri Istini. 2011. Rumput Laut (Pembudidayaan, Pengolahan dan Pemasaran Komoditi Perikanan Potensial). Penebar Swadaya. Jakarta.

Djamin, Z. 1993. Perencanaan dan Analisa Proyek.Fakultas Ekonomi Universitas Indonesia. Jakarta.

Hernanto F. 1989. Ilmu Usaha Tani. Cetakan ke-7.Jakarta.: Penebar Swadaya. 309 hal.

Khordi, M dan Ghufran H. 2010.A to Z Budidaya Biota Akuatik untuk Pangan, Kosmetik dan Obat-obatan. Andi Offset. Yogyakarta.

Rahardi, R. Kristiawati dan Nazarudin. 1993. Agribisnis Perikanan. Jakarta: Penebar Swadaya. 